\section{Extensão universitária e cidadania: desconstruindo para construir}

Sandra De Deus

Pró-reitora de Extensão da Universidade Federal do Rio Grande

do Sul/Brasil. Presidente do Fórum de Pró-reitores de Extensão das

Instituições Públicas de Educação Superior Brasileiras-FORPROEX.
Construir ciudadanía /

Desafíos de gestión

\author{
"Nos teus olhos opacos. \\ Aprendo o que nos distingue. \\ Já repartes comigo a ciência \\ e a paciência. Quero contigo \\ repartir a esperança.
}

\author{
Estrela vigilante em minha \\ fronte. E em teu olhar apenas \\ um tição. Encharcado de \\ engano e cativeiro." \\ (Thiago de Mello)
}

A formação universitária está calcada no ensino, na pesquisa e na extensão. Os princípios da indissociabilidade ensinopesquisa-extensão e os princípios da autonomia universitária estão estabelecidos na Constituição Brasileira de 1988. Portanto, a situação legal está dada. O tripé acadêmico é responsável pela formação de profissionais em todas as áreas do conhecimento que, em situações das mais variadas, ora por força de uma carga horária elevada dentro da sala de aula, ora por comodismo ou por falta de opção, acabam por não conhecer a realidade e tampouco aceitar um olhar divergente. O conceito de Extensão, ${ }^{1}$ definido pelo Fórum Nacional de Pró-reitores das Instituições Públicas de Educação Superior Brasileiras (FORPROEX), em 1987, já defendia, com base no princípio da indissociabilidade, a necessidade de "um currículo dinâmico, flexível e transformador". O contato com as diversas realidades, com as diferenças, com outras perspectivas e mesmo com a crítica são aspectos essenciais da formação profissional. Há, porém, um viés recorrente na formação universitária enquanto local de produção de conhecimento. O não compartilhamento e o descompromisso com questões sociais graves — sejam da arte ou da ciência-gera um distanciamento entre universidade, uma instituição social e com função pública, e a sociedade, que em última instância mantém a universidade como local de formação. Esta contradição tem pelo menos três componentes reais e cada vez mais perigosos: os currículos fechados entre quatro paredes ${ }^{2}$ em que os estudantes necessitam cumprir uma carga horária estruturada em créditos sendo muitos obrigatórios e poucos eletivos; o acomodamento tanto docente quanto discente e a própria estrutura universitária que se coloca distante do cotidiano, dos movimentos sociais, das demandas gerais da sociedade. É mais fácil assistir a uma aula nas salas e laboratórios sem questionamentos (e para muitos estudantes, quanto mais curto o período de aula, melhor), do que confrontar o aprendizado com a realidade. Chauí (2003) diz que

"A partir das revoluções sociais do século XX e com as lutas sociais e políticas desencadeadas a partir delas, a educação e a cultura passaram a ser concebidas como constitutivas da cidadania e, portanto, como direitos dos cidadãos, fazendo com que, além da vocação republicana, a universidade se tornasse também uma instituição social inseparável da ideia de democracia e de democratização do saber".

No entanto, entre o que se prega e o que se pratica, há uma distância marcada pelas dificuldades operacionais, preconceitos e temores que envolvem a manutenção do status quo. Senão vejamos: quais dificuldades se impõem para que a relação entre a Universidade e a sociedade se torne mais horizontal? Como pode a sociedade em seus diferentes graus de representação influir nos conteúdos ou projetos gestados no interior da Universidade? Chauí está correta ao afirmar que educação e cultura são constitutivas da cidadania. Mas qual é a contribuição da Universidade para a constituição da cidadania? Talvez precisemos pensar um pouco sobre a forma como se dá e qual é a qualidade da interação universidade-sociedade. È evidente que a universidade precisa
1) É um processo interdisciplinar, educativo, cultural, científico e político que promove a interação transformadora entre Universidade e outros setores da sociedade.
2) De acordo com o documento "Extensão Universitária e flexibilização curricular", Vol. 04, p. 23, publicado pelo FORPROEX, em 2006, a "sala de aula deixa de ser somente o lócus de produção teórico-abstrata para ser considerada como todo o espaço, dentro e fora da Universidade, onde

se realiza o processo histórico-social, vivido por diferentes atores". 


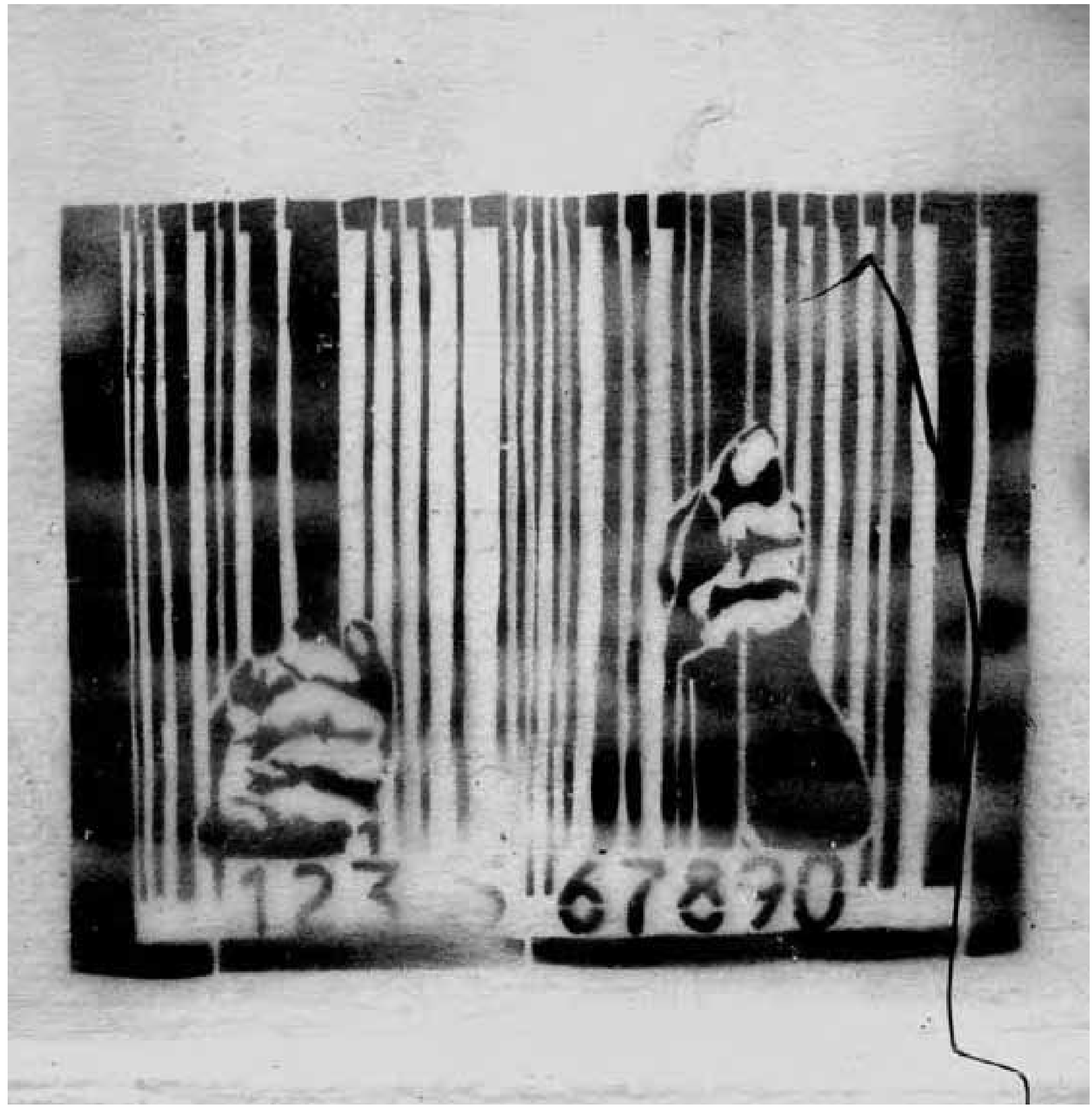




\section{6}

\section{no interior das universidades há um questionamento tornado público que provoca 'prá que serve o teu conhecimento?'}

(re)visitar seus processos de pesquisa e de ensino valorizando os saberes do senso comum, que como prega ao FORPROEX (2006) devem ser

"confrontados criticamente com o próprio saber científico, comprometendo a comunidade acadêmica com as demandas sociais e com o impacto de suas ações transformadoras em relação a tais demandas".

O grande desafio que se coloca para a que a relação universidadesociedade seja mais linear é encontrar motivações que desacomodem docentes e estudantes para atuarem em atividades que não sejam apenas aquelas obrigatórias no currículo, ${ }^{3}$ uma vez que todos estão com muita pressa de cumprir apenas o exigido. Apesar da estrutura rígida dos currículos dos cursos de graduação, a maioria das universidades brasileiras oferece inúmeras atividades —muitas destas com auxílio financeiro- que possibilitam aos estudantes realizar atividades fora dos currículos e que dão outro "brilho" para a formação profissional. Mas ainda o caminho exige vigilância conforme o documento Política de Extensão do FORPROEX ${ }^{4}$

"o ranço conservador e elitista, presente nas estruturas de algumas Universidades ou departamentos acadêmicos e a falta de recursos financeiros e organizacionais, entre outros problemas, têm colocado limites importantes para a implantação e implementação desses institutos legais no âmbito das Universidades Públicas. Muitas vezes, verifica-se a normatização da creditação curricular em ações de Extensão, mas restrições em sua implementação. O mesmo descompasso é verificado quanto à inserção de ações extensionistas nos planos de ascensão funcional e nos critérios de pontuação em concursos e à consideração dessas atividades na alocação de vagas docentes. Nesses aspectos, também em algumas Universidades ou departamentos, o preceito constitucional e a legislação referida à Extensão Universitária não têm tido qualquer efeito sobre a vida acadêmica". (2012)
Duas experiências me socorrem no momento. A primeira é uma pergunta "pichada" em muros que diz: Prá que serve o teu conhecimento? A segunda é uma conclusão do Grupo de Pesquisa Atividades de Extensão do Fórum Nacional de Professores de Jornalismo. ${ }^{5} \mathrm{~A}$ frase/pergunta tenciona, provoca reações diversas, pois soa como uma desilusão em relação ao que se aprende nas escolas e universidades. A conclusão dos professores depois de horas de debate foi de que todo estudante de jornalismo durante a sua formação deve(ria) realizar uma atividade de extensão para ser um jornalista mais completo pois terá um aprendizado confrontado com a realidade. A proposição do GP Atividades de Extensão é válida para outras áreas do conhecimento, pois, ao entender a extensão universitária como espaço de formação que ensina e pesquisa na relação de troca e de comprometimento, abrange um todo e não o específico do jornalismo. Castro (2009) vai direto ao ponto:

"No caso da extensão o que percebemos é que ela produz conhecimento a partir da experiência e assim tem uma capacidade de narrar sobre o seu fazer. $O$ conhecimento narrativo ele não fecha, ele deixa sempre aberto ao final para a possibilidade de se criar outros finais ou se iniciar outros processos. Assim, a forma de produção da narrativa não pretende ser verdadeira objetivamente, mas ser também subjetiva. Além disto, o que se verifica na extensão é um fazer que sempre pressupõe a presença de um outro que não é somente o aluno ou professor, mas um ouvinte".

Vale dizer que se comprova que a universidade, a partir de suas atividades de extensão influencia e é influenciada pelos seus interlocutores. Não significa que ao configurar quais são as tarefas da extensão universitária se desresponsabilize o ensino e a pesquisa de seus compromissos com a sociedade. Assim Severino (2002) se expressa:

"Por outro lado, a universidade, como instituição da esfera educacional, sofre de processo crônico de corrosão interna, deteriorando-se continuamente e comprometendo de créditos curriculares exigidos para a graduação em programas e projetos de extensão universitária".

4) Documento Política Nacional de

Extensão aprovado no XXXI Encontro do Fórum Nacional de Pró-reitores de extensão das Instituições Públicas de Educação Superior Brasileiras em Manaus, maio 2012.

5) O GP Atividades de Extensão dentro do FNPJ (www.fnpj.org.br) já tem 11 anos de funcionamento e faz uma reflexão sobre a importância da extensão universitária na formação de jornalistas. 
sua própria eficácia, tornando-se pouco fecunda no atingimento de seus objetivos, consagrados pela tradição e reiterados pela retórica dominante".

A sociedade, através de seus diferentes atores pode demandar à universidade uma atuação mais pró-ativa. A Universidade Federal do Rio Grande do Sul, através do Departamento de Educação e Desenvolvimento Social realiza já alguns anos um programa de formação para professores da rede pública da região metropolitana de Porto Alegre em educação antirracista no cotidiano escolar. Participam professores e educadores das redes públicas de ensino, especialistas e profissionais de instituições diversas, pessoas leigas comprometidas com ações que integram as políticas sociais e educativas locais e regionais e estudantes de graduação e pós-graduação. Esta iniciativa parte do compromisso social da Universidade, como instituição de ensino superior responsável pela formação inicial e continuada de educadores e indutora de práticas antirracistas tanto na universidade quanto em escolas de educação básica. Por este motivo, todas as ações de formação realizadas são planejadas e executadas coletivamente por agentes institucionais de diferentes instâncias educativas. Não significa, porém, que estas ações aconteçam sem "dor", pois, muitas das atividades implícitas no Programa só se realizam a partir de esperançosas e forçadas posições pessoais, uma vez que no interior da universidade e em todos os espaços institucionais o racismo e a discriminação estão impregnados. Portanto, a sociedade pode influir em projetos gestados no interior da universidade, como no exemplo apontado, e com isto a Universidade contribui para a construção da cidadania. Santos (2010) considera que

"De qualquer forma podemos observar que, apesar dos conflitos entre os agentes internos ou os interesses externos (Estado e setores sociais), a extensão universitária, hoje, é uma atividade que tende a consolidar-se como resposta aos desafios colocados às universidades públicas e privadas brasileiras, tanto por aqueles que querem flexibilidade, competição e eficiência, quanto por aqueles que exigem um caráter mais popular. Em outros termos, isto significa dizer que a formação universitária deve ser efetivada com amplitude maior que a da profissionalização em sentido restrito para que se transforme num horizonte mais amplo de estudo e produção e socialização de conhecimentos".

Neste caso há que se abrir espaço para desconstrução de preconceitos históricos e extrair da extensão o que ela nos proporciona de melhor: a possibilidade de conhecimento e compreensão de realidades e comportamentos, a partir de vivências diferenciadas, ainda timidamente presentes em ações educacionais de um modo geral. Não há dúvida nenhuma que considerando toda a importância da pesquisa e do ensino, realizar ações que envolvam outros interlocutores, que não apenas o professor e o aluno, agregam valor e demandam um esforço maior dos envolvidos.

A Extensão é o lugar da "alteridade" por excelência. Onde a Universidade realiza o reconhecimento da diversidade sócio-cultural e etnicorracial e permite a construção e o estabelecimento dos compromissos necessários à leitura do mundo. Ao atuar nas dimensões estéticas e culturais, a extensão universitária tenciona o ensino e atualiza a pesquisa. Este movimento nos convoca não só a pensar o lugar da extensão na formação cidadã dos envolvidos, como também reconhecer o seu papel real e objetivo na estrutura da universidade no cumprimento daquela que pode ser uma de suas tarefas mais generosas e instigantes, a de ser o local de formação, contribuição e promoção de propostas para melhoria da vida. No interior das universidades há um questionamento tornado público que provoca "prá que serve o teu conhecimento?" e no seu exterior há uma latente necessidade de profissionais com outras competências, que vão além da técnica, que contribuam na promoção do desenvolvimento da sociedade em todas as suas dimensões.

\section{Bibliografía}

Castro, Luciana Maria Cerqueira (2009). "A universidade,a extensão universitária e a produção de conhecimentos emancipadores." Texto extraído do projeto de Tese: A Universidade, a Extensão Universitária e a Produção de Conhecimentos Emancipadores (ainda existem utopias realistas) apresentada ao Instituto de Medicina Social/ UERJ como requisito para a qualificação do Doutorado em Saúde Coletiva.

Chauí, Marilena (2003). "Conferência na sessão de abertura da 26a Reunião Anual da ANPEd." Realizada em Poços de Caldas, MG, em 5 de outubro. Revista Brasileira de Educação, Set/Out/Nov/Dez, nº 24.

FORPROEX (2006). Indissociabilidade ensino-pesquisa-extensão e a flexibilização curricular: uma visão da extensão. Brasília.

Mello, Thiago de (1981). Mormaço na Floresta - poesia Lição de escuridão. Rio de Janeiro: Civilização Brasileira.

Santos, Marcos Pereira dos (2010). "Contributos da extensão universitária brasileira à formação acadêmica docente e discente no século xxi:um debate necessário." Conexao UEPG, nº 06.

Severino, Antônio Joaquim (2002). "Educação e universidade: conhecimento e construção da cidadania." Revista Interface - Comunic, Saúde, Educ, Vol. 6, nº 10, pp. 117-124, fev. 